\title{
Prehistoric Goldwork in Western Europe
}

\author{
Christiane Eluère \\ Musêe des Antiquités Nationales, St. Germain-en-Laye, France
}

\begin{abstract}
The study of objects of gold from prebistoric times constitutes a special field of archaeological research, and that of the many such objects from the Bronze Age (from around 2000 to 700 B.C.) in Europe presents many challenges.
\end{abstract}

Systematic studies (1-5) have been made of prehistoric gold work from many regions of Europe. These have included a consideration of relevant archeological and environmental information from which much relating to its symbolic character has emerged. They have also included regional studies of the typology of such goldwork. Finally they involve, now, examination of these artifacts from the points of view of their structures, the nature of the alloys used in their fabrication and the techniques by which they were made. The results of these various investigations provide the basis for the broad discussion of prehistoric goldwork in Western Europe which follows.

Technical studies of prehistoric golds make it possible to obtain information about:

(1) The uniform use of well identified processes and their cultural or territorial allocation (cultural considerations)

(2) The connections between forms and techniques, resulting from adaptation or transposition (aspects of contact or movement)

(3) The identification of fabrication methods and the manner in which they were conditioned by the quantity and quality of the raw materials at the disposal of the goldsmiths (distribution dependence on raw materials)

(4) The distinguishing of the parts played by individual creativeness and collective traditional workshops (organisation of gold craftsmen).

In order to focus the problem correctly it should be recalled that the biggest centres producing gold artifacts during the Bronze Age were: Ireland, Great Britain, the Iberian peninsula and Northern Europe. Central Europe, which derived much of its material from the large gold lodes of Transylvania was another big production centre. In Western Europe, the extent to which gold artifacts have been found varies from region to region. Thus, the gold treasures discovered to date in Great Britain (approximately 500 pieces) and in France (around 400) are, in comparison with those of Ireland $(1000)$, respectively 5 and 16 times less important. These differences probably reflect variations in supplies of raw materials, in demand for such artifacts and in economic, social or religious circumstances.

\section{Funeral Ornaments and Treasures}

Thus, characteristics of the use of, or concepts surrounding, gold in prehistoric times are revealed by study of the circumstances of final abandonment, or deposit, of the gold artifacts. Small beads, little foils or trinkets were often left in burial places, small personal ornaments of the deceased being left attached to the person. Large pieces of jewellery (necklaces, bracelets) are frequently discovered, in contrast, assembled in hoards or isolated, under one or several stones, or in containers such as wooden boxes, sacks made of natural fibre, and bronze or ceramic vases - the finds corresponding, then, more to a kind of heritage collection when the objects are numerous. They might also have constituted offerings, even where there were only one or two pieces. The gold artifacts abandoned in the bogs of Scandinavia and Ireland exemplify this. Large jewellery pieces are rarely found on the body of the deceased except, in some cases, in a very ostentatious manner, indicating the person's high social standing.

A last type of discovery is that of assemblies of small bars, relics and ingots, hoarded in vases, along with other objects assembled for remelting, and sometimes buried or hidden in settlements. Finds of this type clearly constitute stores of metal waiting to be worked or reworked.

With regard to the oldest goldwork, which appeared at the end of the third millenium, in the Mediterranean areas of France and Spain, and later along the Atlantic edge of Europe, its use seems to have been that limited exclusively to small gold decorative items in the burial ritual. Subsequently, when gold working truly developed, in the Early Bronze Age and up to the Late Bronze Age, gold hoards appeared in great number in all of the Atlantic areas of Europe, while in the eastern and central Continental areas, the middle of France, Germany, Denmark and Sweden, similar finds also exist; however, the gold abandonment ritual in certain tombs is still a feature of this period. Most of our observations concerning ritual practices, and those about forms of gold objects, allow us to separate sufficiently well the following two culturally different areas in Western Europe: the Atlantic and the Continental areas.

\section{Prehistoric Goldsmiths}

The goldsmiths themselves did not leave many traces of reliable remains: we have small anvils, hammers, chisels and dies, in bronze, which could have been part of their equipment, but we cannot distinguish these from the ones which were available for use in bronze metallurgy for miniature work in 
copper-based metal. Perhaps they were the same? Meanwhile, accompanying some gold discoveries, in Normandy and in Scotland, here and there an assembly of bronze tools which must have been those of metalworkers, have been found associated with gold items (Fresné-la-Mère, Ardabrock). On the other hand numerous pieces of equipment must have been made from horn or in various woods, or stones, for example mallets or tools for polishing or for beating.

Small parallel-sided, hard rock blocks, like one which has been found recently in a spacious settlement from the 9th-8th century B.C. north of Paris and which carries traces possibly connected with goldwork, may have constituted a form of anvil block. With regard to ingots, the shapes of some of them are known: small plano-convex masses, of the form obtained by casting in a small crucible, bars plaited or rolled in the shape of rings, or thick wires rolled in spirals or plaits.

Although one may have occasional, strong clues about the places where metal, sometimes gold, has been worked, the lack of documents identifying any prehistoric gold workshops or their equipment, forces us to determine from the finished objects themselves the different types of operations which they underwent.

The present paper is based particularly on the archaeological study of the prehistoric gold of France; its objective is to stress the importance of the information that one is in a position to get from methodical, technological examinations (spectrographic, microscopical observations, experimentation) which, as far as possible, could be carried out on the largest number of objects. These do attempt to contribute to a better co-ordination of the different directions taken by the archaeological survey as a whole.

\section{The Prehistoric Techniques}

\section{About 2000 B.C.}

Ancient Metbods Common to Copper, Lead and to Silver Used for the Fashioning of Small Ornaments in Gold

The most ancient Western European golds appeared at the end of the third millenium in the part belonging still to the Neolithic period, in which, however, beads, awls or dagger blades in copper, and lead beads, were the first tentative workings in metal. Gold work was largely restricted to rolled threads, some massive beads being obtained by casting or hammering when hot, by methods which were not specifically for gold but, at the same time, were used for copper or lead, reproducing, furthermore, the same simple shapes (6).

It is particularly in the following period, the Chalcolithic period or Copper Age, that small pieces in gold were obtained exclusively by hammering or beating (Figure 1). Such pieces were of small rectangular appliques, occasionally folded at the borders, perforated at the edges, long ribbons of sheet metal

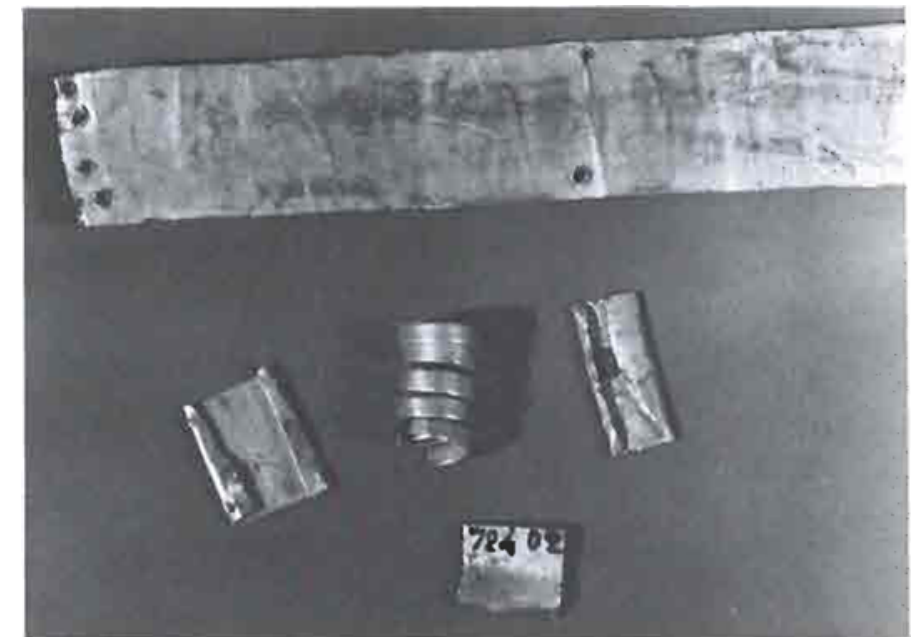

Fig. 1 Small trinkets of gold jewellery together with a beaten ribbon or band of gold dating from about 2000 B.C. (Kerouaren in Plouhinec, Morbihan, France)

wrapped in cylindrical beads, measuring between 1 and $10 \mathrm{~cm}$ or more. Pieces of larger size, such as headbands, consisted of long beaten ribbons. The standard shapes of these forms in gold can be recognized all over the Atlantic coast of the continent, principally from Portugal to Brittany, and, to a lesser extent, in the Pays-Bas. The gold work in the British Isles appeared only during the course of this period, in different forms, yet always from beaten, thin sheet metal, occasionally very large disc plates, earrings in bent sheet, etc.

Fig. 2 Detail of a golden necklace, the front part of which is cut up into thin flexible strips (Rondossec, Morbihan, France). Beginning of the Early Bronze Age

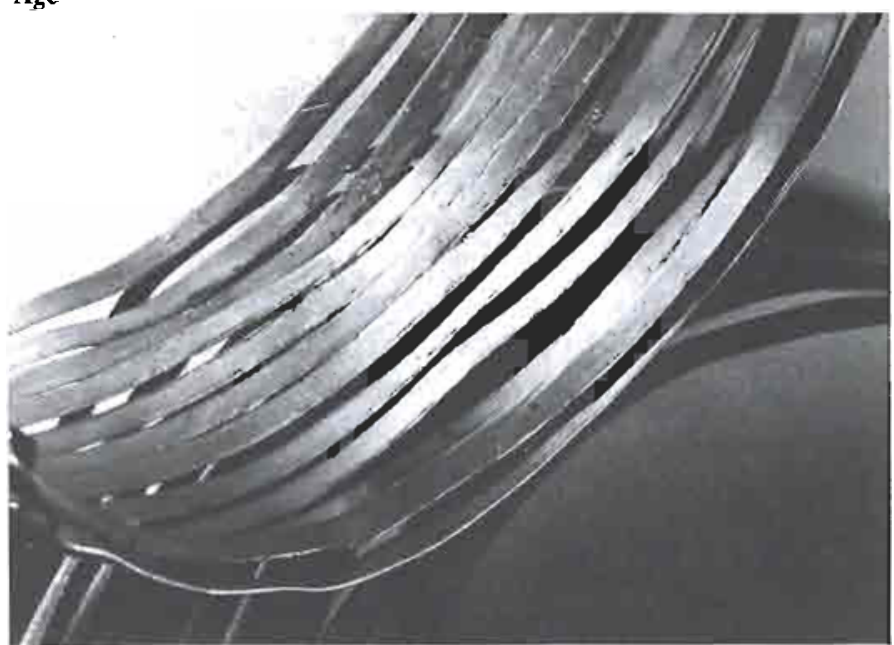



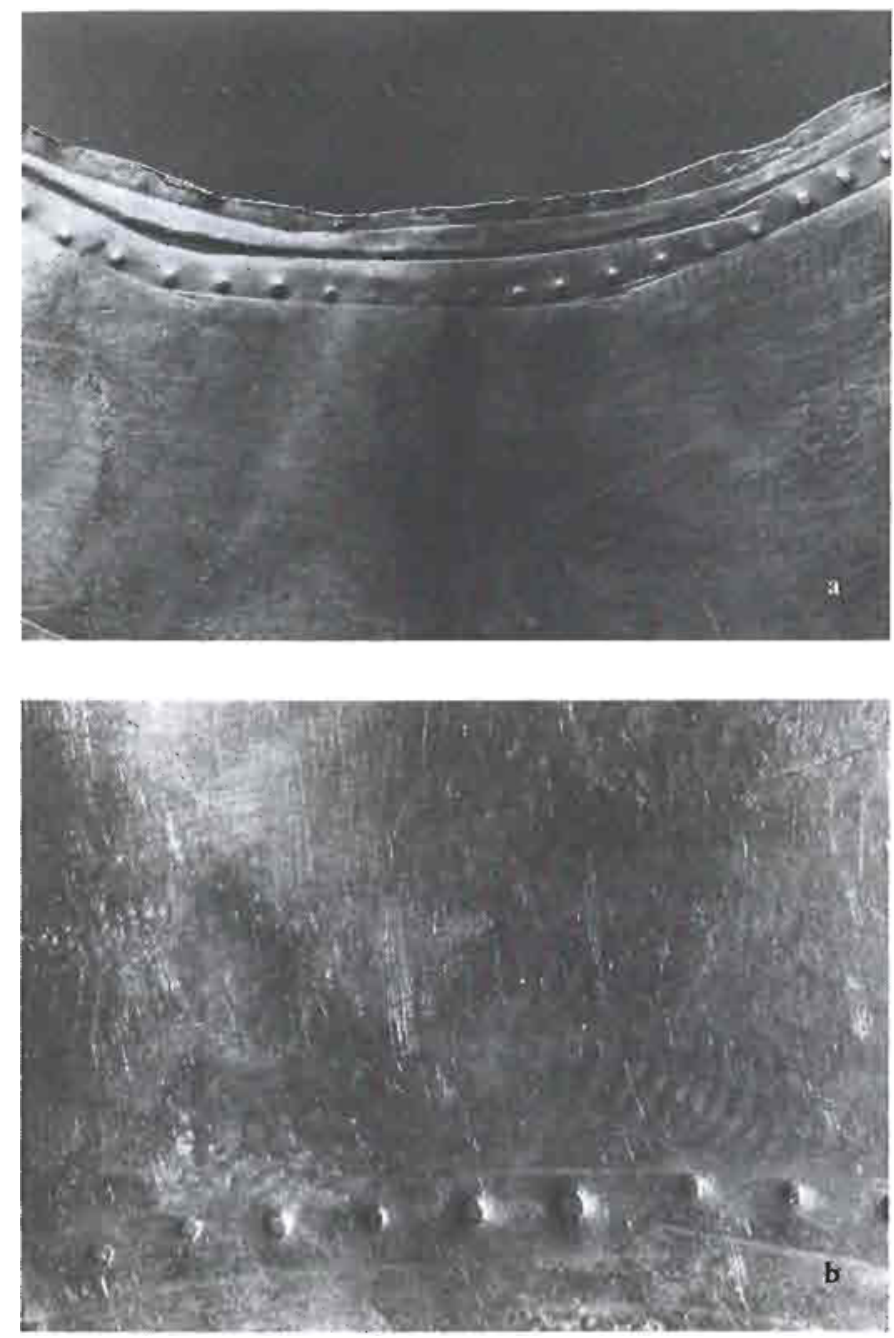

Beginning of the 2 nd Millenium B.C.

Goldworking of Beaten, Large 'Ritual' Jewellery in the Atlantic Area

In the Early Bronze Period, a genuine copper alloy metallurgy became established (copper with arsenic, and with tin), and also a specialist craft in gold. Beating gold sheet or leaf was always the basic technique used on the Atlantic coast and in the British Isles. Large ornaments in gold were more frequent from this time: a series of cylindrical necklaces (Figure 2) spreading in occurrence from Portugal to Brittany introduced a new type of decoration brought about by cutting parallel incisions into the anterior face of a piece of jewellery; the cuts were carried out on the external face, each lamella having a re-entrant border onto the internal face. With these découpés decorations is sometimes associated a dot-line decoration made by au repoussé work, using the impression of sharp tools like needles of bone or wood into the internal face of a metal sheet.

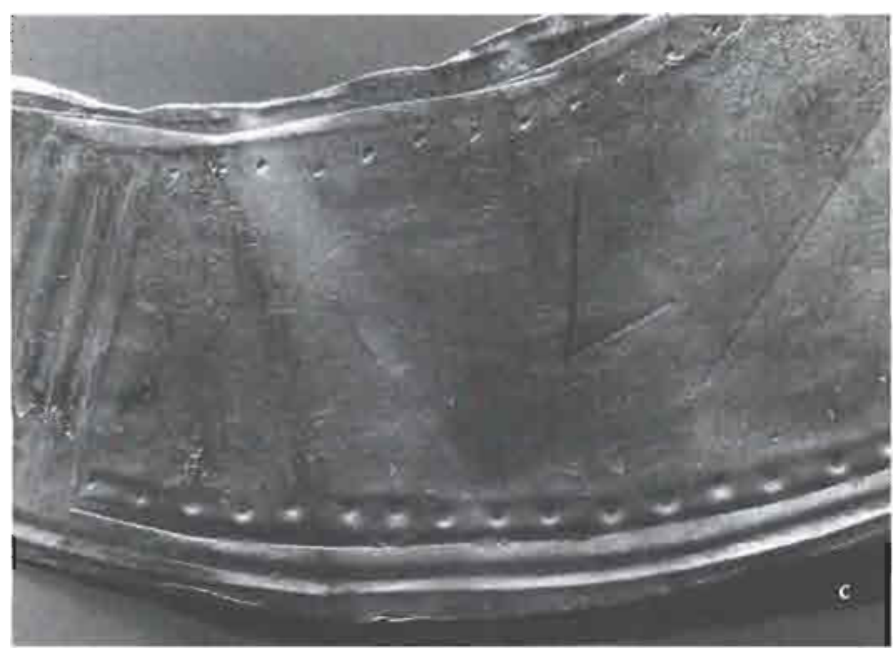

Fig. 3(a) Detail of a lunula or breastplate in the shape of a croissant decorated with points en repoussé. This external face has indented lines which reveal many chisel failures while, on the surface, striations can be seen which are possibly due to the placing of a piece of skin over it while it was being beaten. The inside edge of this neckpiece has been finished off clumsily and traces of folded metal can still be seen. Early Bronze Age, 1800-1500 B.C.

Fig. 3(b) Detail of a position on the external face showing the area corresponding to the points en repoussé as seen in Fig. 3(a)

Fig. 3(c) Further detail of the internal face of the same lunula (Kerivoa in Bourbriac, Côtes-du-Nord, France). Early Bronze Age

From this epoch emerged a centre of gold-working, perhaps the most important of all Western Europe: in Ireland the Atlantic tradition of beating was highly developed and used successfully in the production of large crescent-shaped gold breastplates called 'Iunulae' (Figure 3). These are found widespread throughout Ireland. The fashion spread to a lesser extent through Scotland, Cornwall, France, Britain, Northern Europe and also as far as Portugal. The technologies were well differentiated by the influence of regional groupings in their production of the same type of ornament. Thus, in Ireland, most of 80 lunulae which have been found were made of leaf which on average reached $0.20 \mathrm{~mm}$ in thickness with an average width of $71.32 \mathrm{~mm}$ for the most beautiful examples, which are decorated with geometrical engraving. The more modest lunulae constitute another series which, with an average thickness of $0.22 \mathrm{~mm}$, have an average maximum width of only $40.06 \mathrm{~mm}$. On the continent, and also in Great Britain, another fabrication group, less refined, can be distinguished; in 
this group the average thickness is $0.39 \mathrm{~mm}$ with the maximum width averaging $55.89 \mathrm{~mm}$. The average masses of the two series of lunulae of Irish fabrication are 54.3 and $40.1 \mathrm{~g}(7)$, but certain continental lunulae are 3 to 4 times heavier! The decoration of the latter is much simpler, being again composed of points or lines produced au repoussé, engraved deep or zigzag and arranged around the perimeter of the piece. While the Irish engraved patterns are of a remarkable quality, and groove the metal in general only very superficially, some decorations on lunulae found in Brittany, for example, are deeply cut and the repetition of small marks from the engraving tool is occasionally clearly visible. (Figures 4 and 5)

Two other areas are distinguished by very specific goldworking technologies. The South of England which one associates with, at that time, a brilliant culture, called the 'Wessex culture', has yielded in the tombs of people of high rank, pendants often consisting of amber set in gold leaf, testifying to a varied practice of the art of sertissage. In Brittany it is principally another speciality which is manifested, that of incrustation with thousands of minute gold studs of the cloth hilts of swords and daggers, belonging to certain noble warriors. The geometrical patterns used have not always been possible to restore.

These tiny studs are of the order of $1 \mathrm{~mm}$ length and $0.5 \mathrm{~mm}$ in cross-section; they would have had to be obtained by twisting a thread which was re-heated and then cut into sections.

Outside the Atlantic region, it is in this phase of the Bronze Age that the gold work is manifested simultaneously in almost all the Western European regions; nevertheless in the North of Germany and the East of France, which were then linked more to a central European cultural area, objects cast in gold - that is to say, produced by the same techniques which yielded the same forms in bronze - appear, such as some types of pins. These regions also produced numerous fine rolled wires, open-ended, or occasionally double because of their ends being soldered together.

\section{About 1500 B.C.}

Diversification of Techniques. Special Applications of Beating a) Twisted Torcs of the Atlantic Zone

From the middle of the Bronze Age, a feature which is increasingly common in decorative ornaments from virtually the whole of Western Europe was the use of spirally twisted metal bars or bands. They were used in ornaments of bronze and gold, with some regional variations. Thus, the ends of Scandinavian bracelets were often spiralled and the large torcs of Britain and Brittany were typically embellished by affixing conically shaped knobs at their ends. The exact manner in which the long torcs were used or worn is not known for certain. They were often over a metre in length and therefore long for use as belts or girdles.

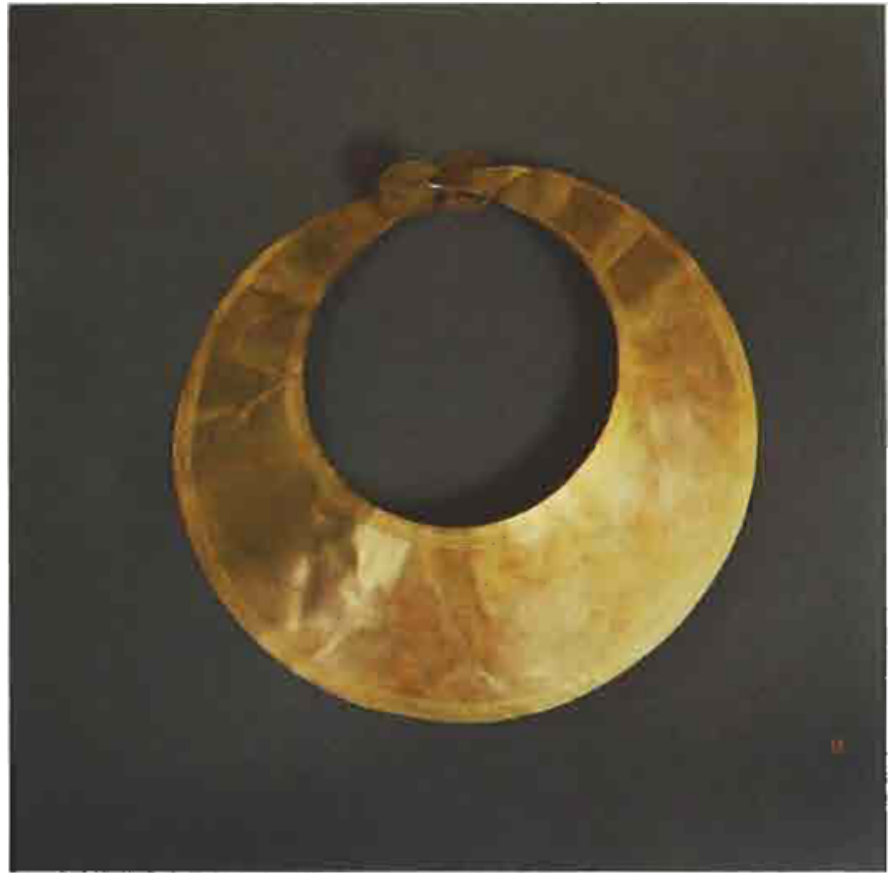

Fig 4 Lunula with incised decorations (Saint-Potan, Côtes-du-Nord, France). Early Bronze Age

Fig. 5 Detail of the lunula from Saint-Potan showing the deep incisions around it

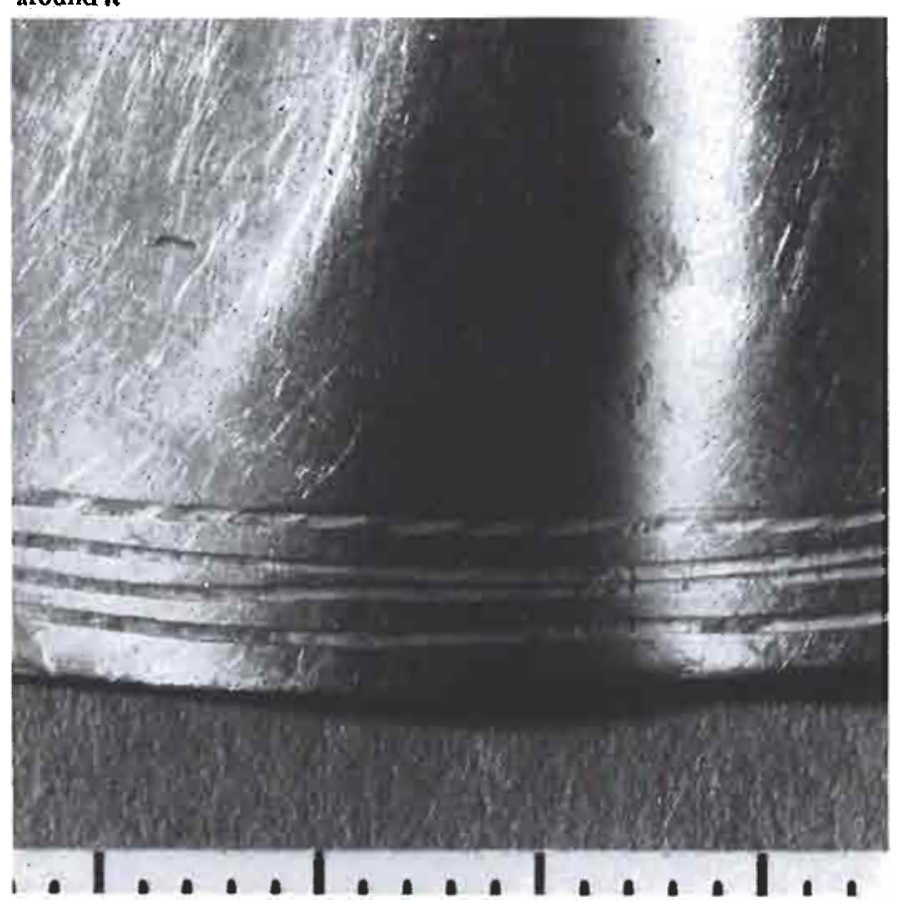




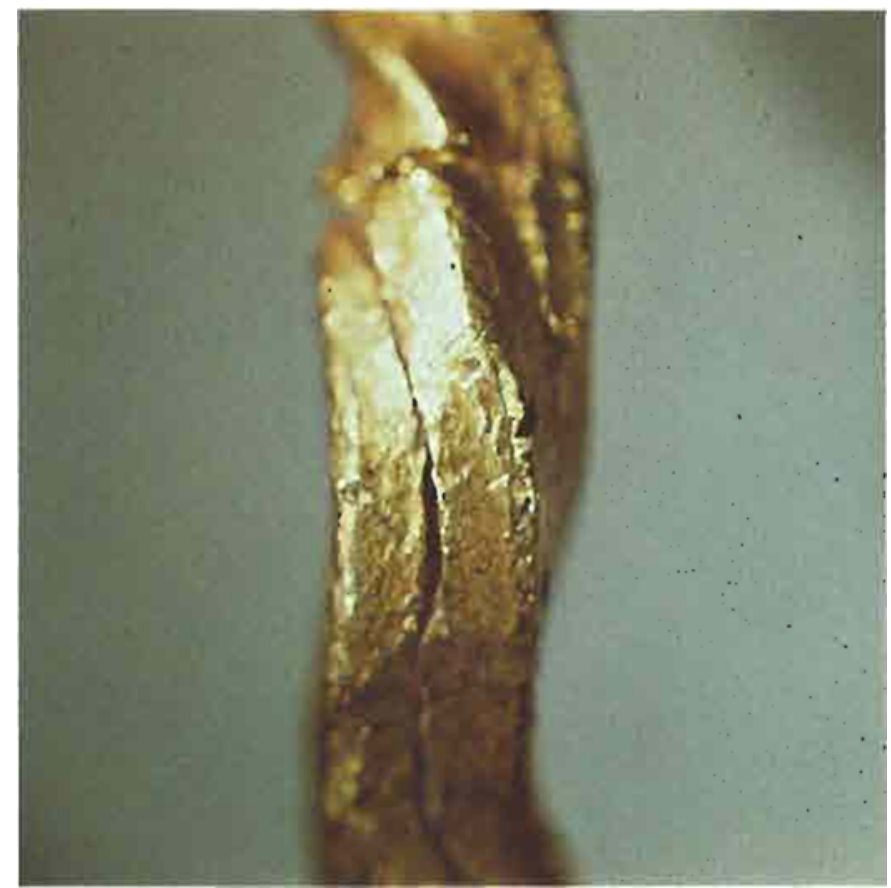

Fig. 6 Detail of cracks in a twisted torc made from rod in square cross-section (Necklace from Jaligny-sur-Besbre, Allier, France). Middle Bronze Age, $1500-1200$ B.C.

Fig. 7 The 'treasure' of Rongères (Allier, France). The gold jewellery was found in the beaten gold goblet which is decorated both en repoussé and by stamping. The bracelet has sides with decorations in relief and points in cross-shaped patterns which must have been made by punching. The spirals are made from a double threaded strand of metal and are soldered at their ends. Middle Bronze Age

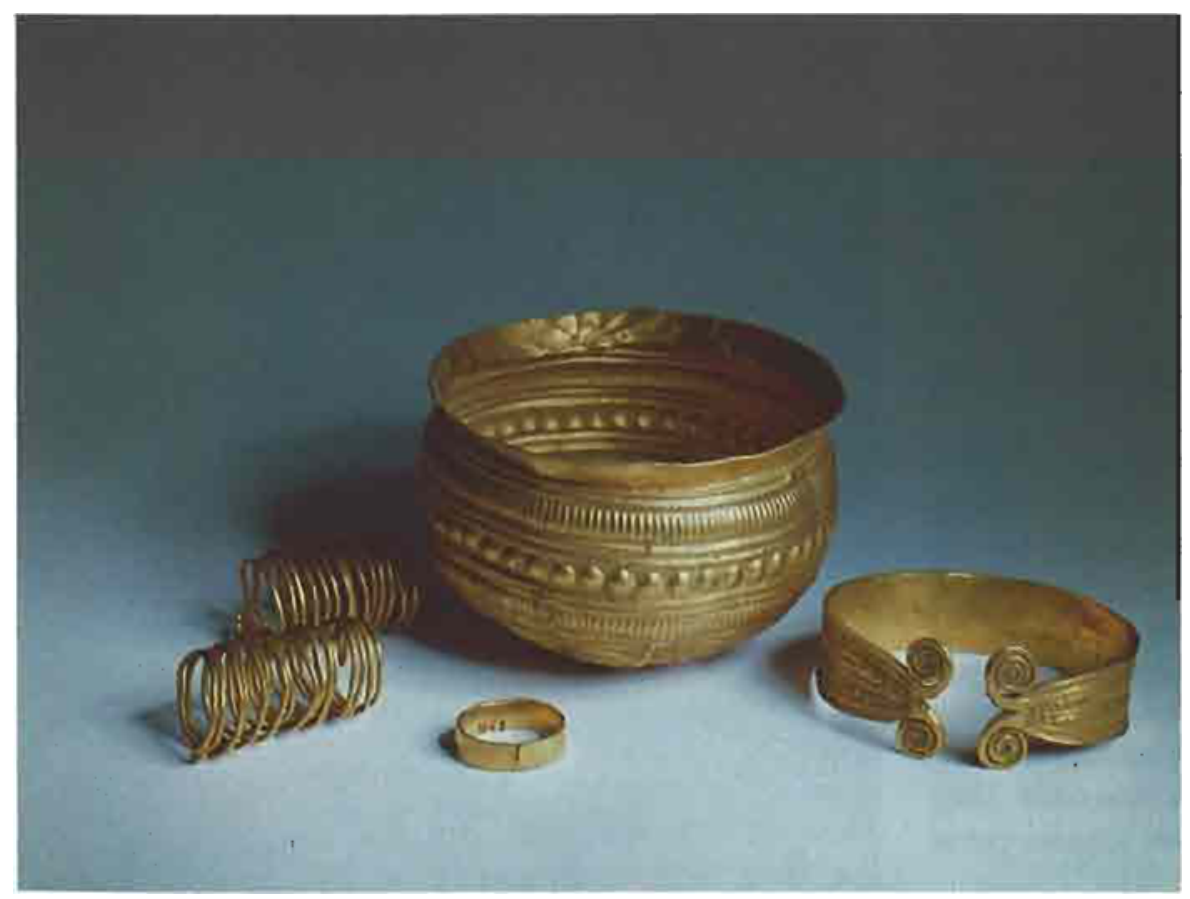

The 'twisted' theme also became prevalent in the designs of earrings and necklaces. These smaller items were most frequently made from a stem or rod of metal which was beaten to a square cross-section and then twisted. The surfaces of torcs made in this way exhibit fissures and cracks (Figure 1) which, without doubt, resulted partly from the presence of impurities which were not eliminated from the metal before use, and partly from excessive cold working of the metal during beating.

The longer 'belts' or 'girdles' on the other hand were made by twisting rods which, although initially of quadrangular crosssecrion had been carefully beaten to a cruciform cross-section. For many years it was believed that this latter cruciform crosssection was achieved not by beating but by the soldering together of two longitudinally folded strips. Recent studies have failed, however, to reveal any vestiges of solder and it appears that it was produced by beating in a gutter of right-angular section. Experiments carried out using a bar of lead have demonstrated that this technique poses no major difficulty (8).

Although the twisting of rods of square cross-section is a feature of ornaments common on both sides of the Channel, and from Northern Europe, that of rods of cruciform crosssection is a feature only of Britain and the North West of France.

Rings and bracelets incorporating twisted designs were produced also in Central Europe but it appears that they were fabricated by casting and this sets them apart from corresponding material from Western Europe.

(b) Decorated Foils from Northern Continental Europe

The beating of gold into foil or leaf developed in Continental Europe especially in the Middle and Late Bronze Ages (1 500 B.C. to 700 B.C.), but for the fabrication of ornaments different in type to those discussed above. The very thin foil or leaf, produced in round, oval or rectangular shapes, was embellished au repoussê, or by stamping upon a predecorated bronze base, or with the aid of patterned dies.

The decorations were frequently inspired by the theme of concentric circles or bumps in lines, themes which we find on a large series of beautiful gold vessels from Northern Germany, Scandinavia and especially Denmark, and the most Western finds of vessels of this type have been in France (Figure 7). The vessels are in the form of small bowls of different hemispherical designs, sometimes with a vertical or inclined collar. Their dimensions do not vary 


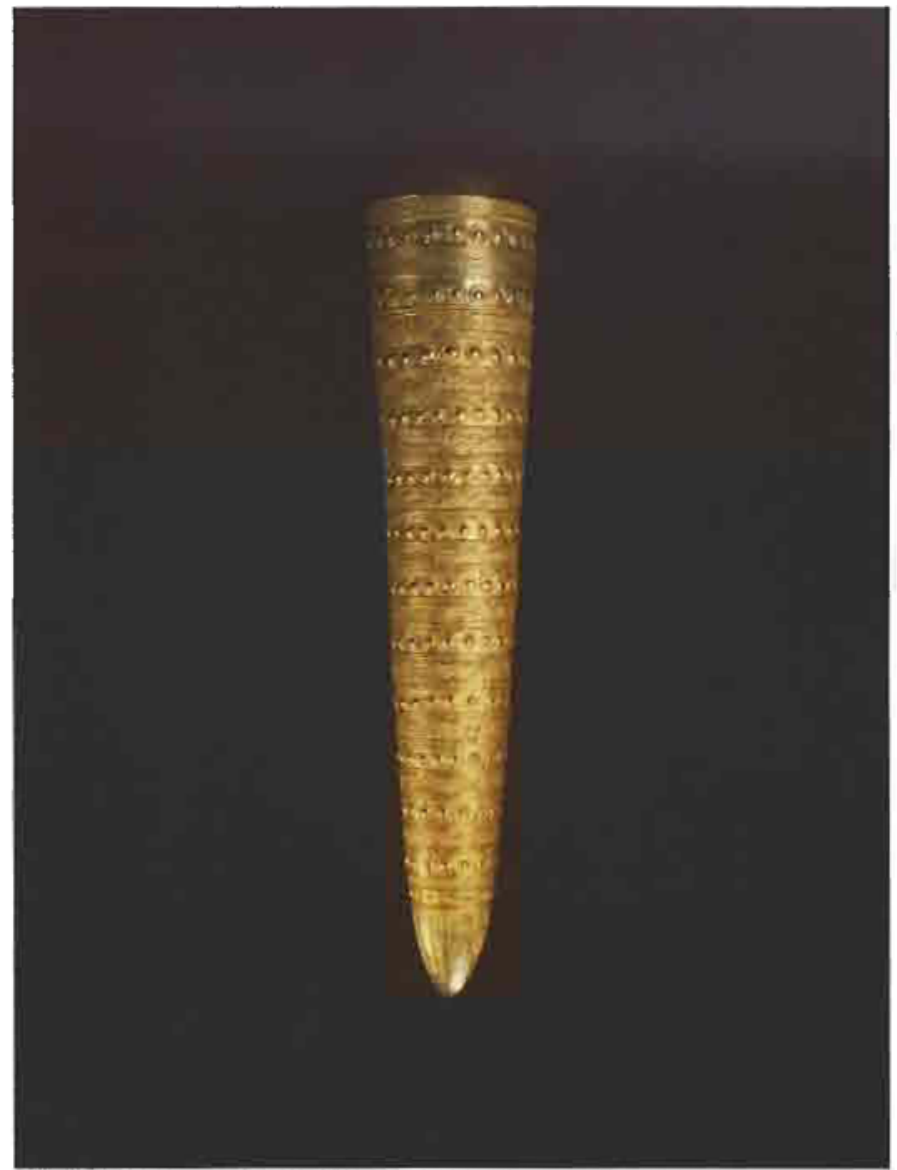

Fig. 8 A tall conical vessel from Avanton (Vienne, France). Its height is $53 \mathrm{~cm}$ but it is possible that as originally produced it had a flanged brim

greatly, the bowls being between 10 and $20 \mathrm{~cm}$ in diameter, and they were made by beating the metal into thick foil discs, then working these into hemispherical shape, and finally beating decorative designs on the sides. Some examples are somewhat exceptional in shape. Thus three vessels have been found which are conical in shape with pointed bottoms - two in Southern Germany and one in Central France (Figure 8 and 9). With a maximum diameter of about $15 \mathrm{~cm}$, heights of up to around $0.9 \mathrm{~m}$ and foil thickness of 0.1 to $0.2 \mathrm{~mm}$ these pieces display no traces of soldering or joining and must have been made from one piece of metal. It has been calculated by Dr. Foltz from the Rönisch Germanisches Zentralmuseum of Mainz, (9) that they must have been very patiently beaten from metal discs which could have been about $12 \mathrm{~cm}$ in diameter and $2 \mathrm{~mm}$ in thickness. Their decoration, which covers the whole of their surfaces, must also have been a major task. It must have been achieved by the repeated use of designs mounted on a wooden model or form, or alternatively by the beating of the golden

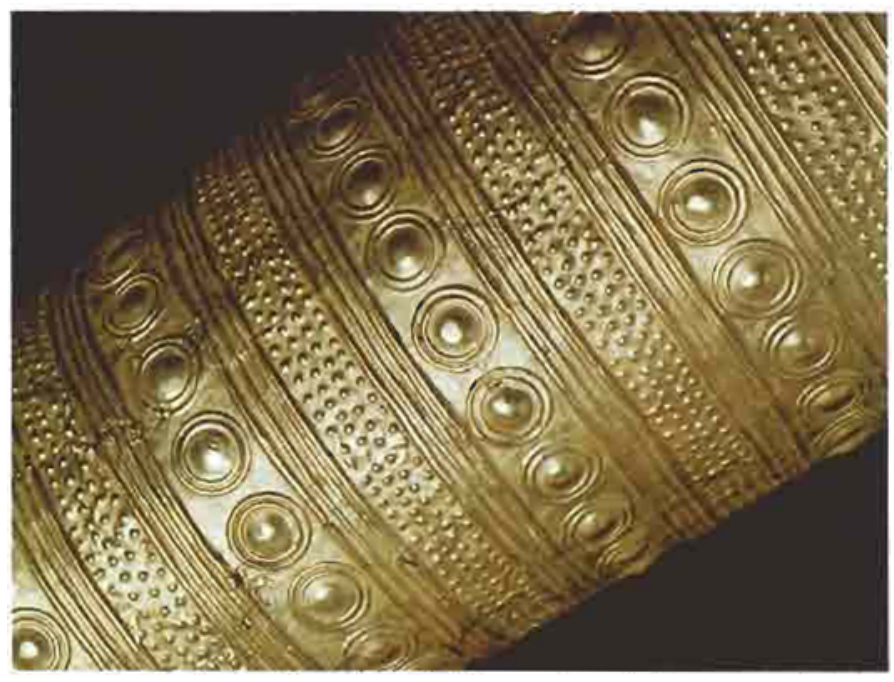

Fig.9 Detail of a vessel from Avanton (Vienne, France). The concentric circles used in its decoration range respectively in diameter from 0.65 to $0.30,1.0$ to $0.6,1.1$ to $0.7,1.3$ to 0.85 and 1.3 to $0.6 \mathrm{~cm}$

Fig. 10 A chain of coiled bracelets. Two of the bracelets' links have decorations in relief and have been cast. They come from the centre of France (Saint-Babel, Puy-de-Dôme) and exemplify the traditional character of gold-working in the continental zone. Middle Bronze Age

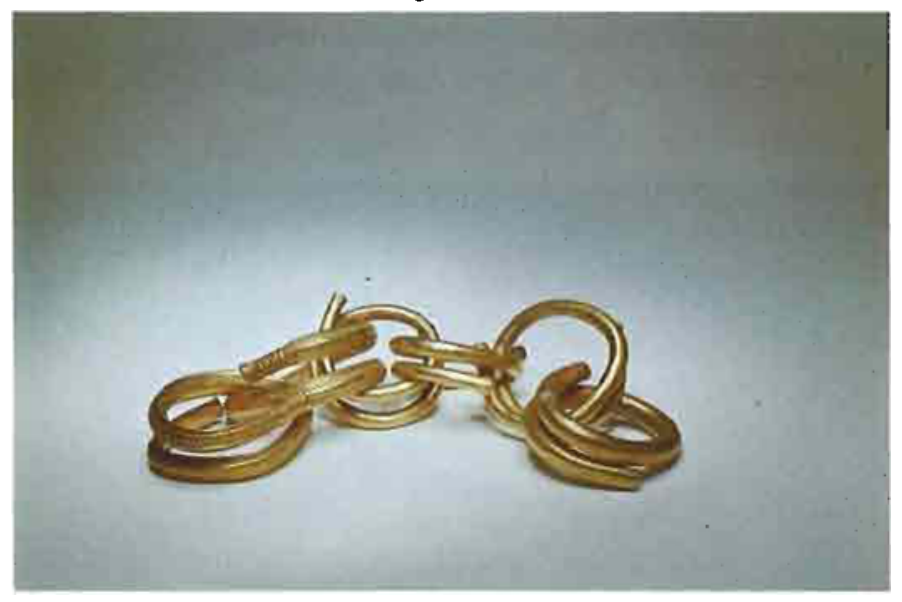

cone on a decorated bronze model. In the case of one of the vessels from Southern Germany it has been estimated that it must have been necessary to use 25 different dies in order to produce 108 decorative patterns. Each of these patterns had to be generated by working on the internal surface of the cone. In order to achieve this using such a thin foil it must surely have been necessary to protect the external surface from the shock effects of the mallet blows, probably with animal skins. 


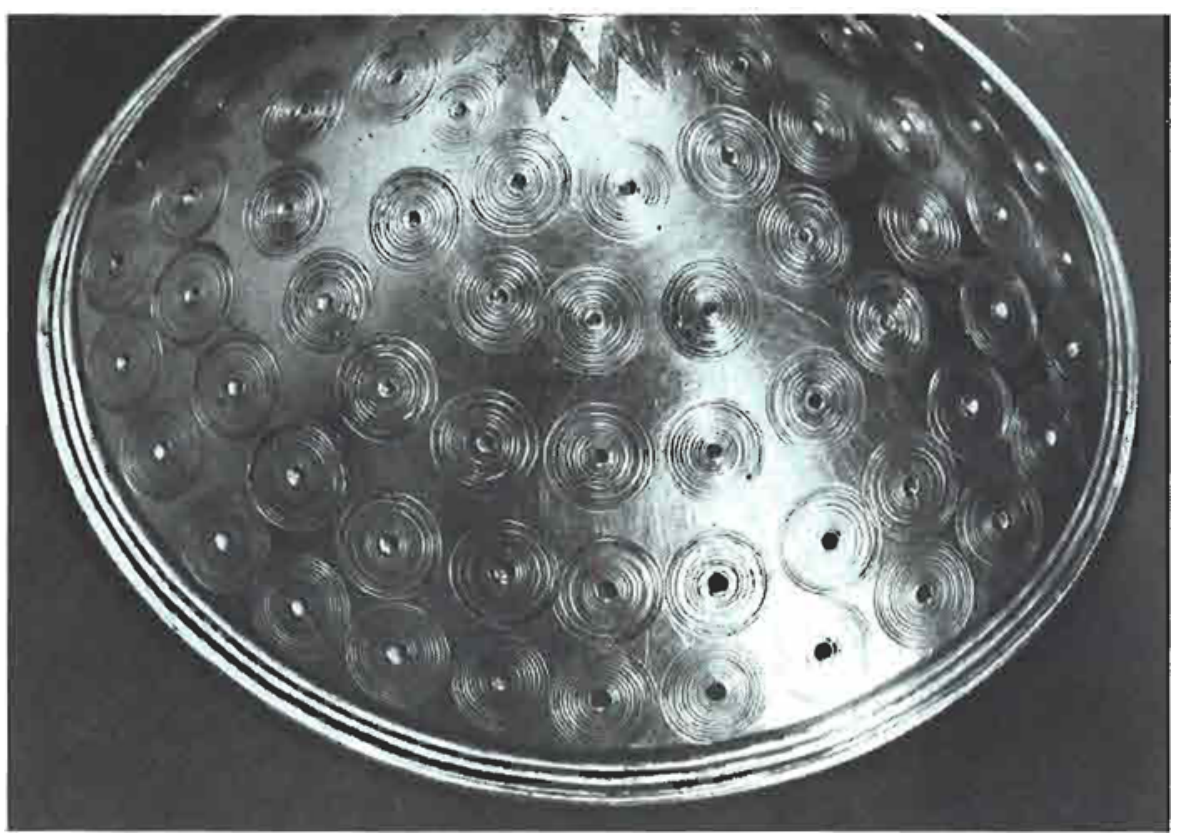

Fig. 11 Dress fasteners from Clones (Co. Monaghan, Ireland). The fine decoration of one of its ends with concentric circles (using a compass) is shown here. 8th century B.C.

\section{8th Century B.C.}

\section{Developments at the End of the Bronze Age}

After 1000 B.C. changes in the material traces of the various cultural groups and, in particular, changes in their gold jewellery and ornamentation became evident.

Countries such as Ireland had developed a flourishing jewellery industry in which some of the latest additions to goldworking technology were practised. These included the creation of pieces in filigrane, and of buckles made of gold threads twisted and soldered (lock- or hair-rings) in which the threads were as little as $0.3 \mathrm{~mm}$ in diameter (4). They were, in addition to current sophisticated techniques such as that of decorating bronze rings with alternate bands of silver and gold, and that of

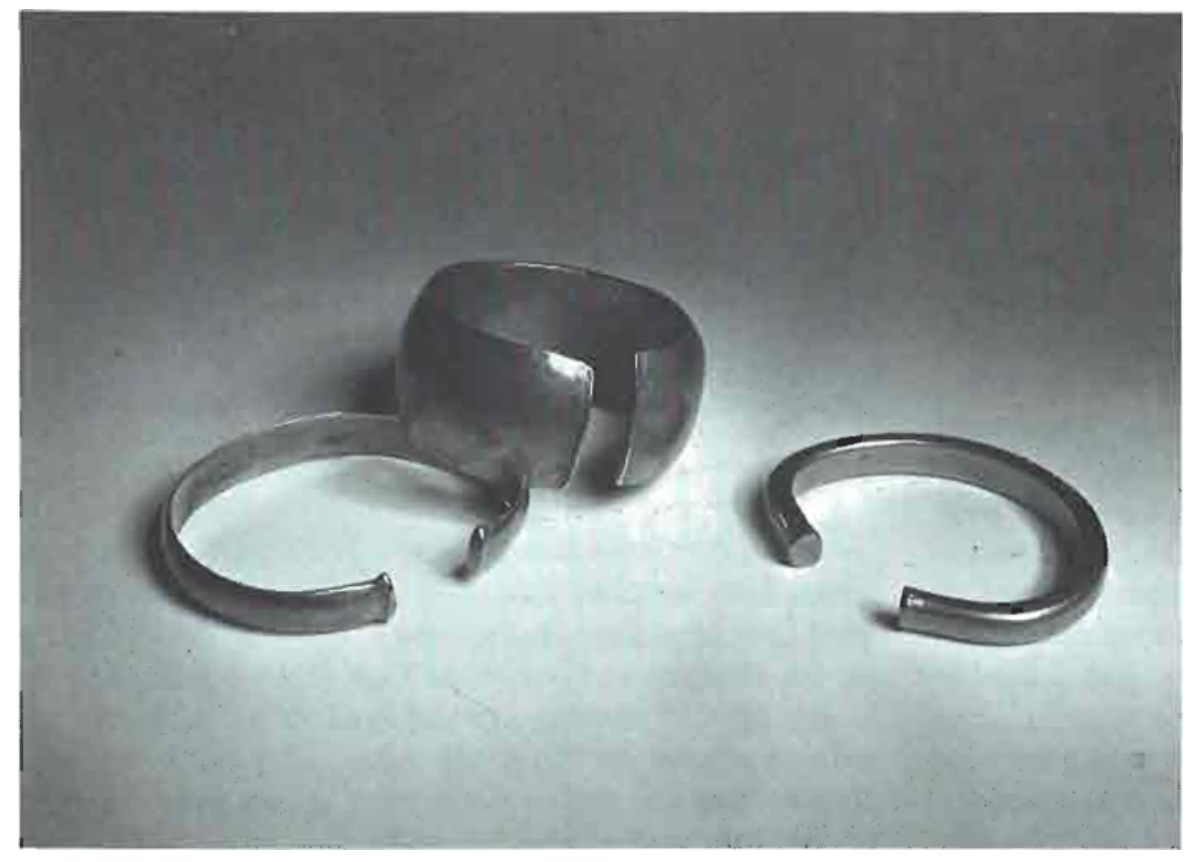

Fig. 12 Bracelets from the end of the Bronze Age. On the internal face of the centre bracelet marks from the beating of the metal can be seen (Brittany, France). Late Bronze Age, 1200-800 B.C. 
Fig. 13 Detail of a large beaten bracelet with shallow incisions at its ends. The oblique markings are more definite than the horizontal ones which show signs of numerous difficulties encountered by the artist (Matignon, Côtes-du-Nord, France) Late Bronze Age

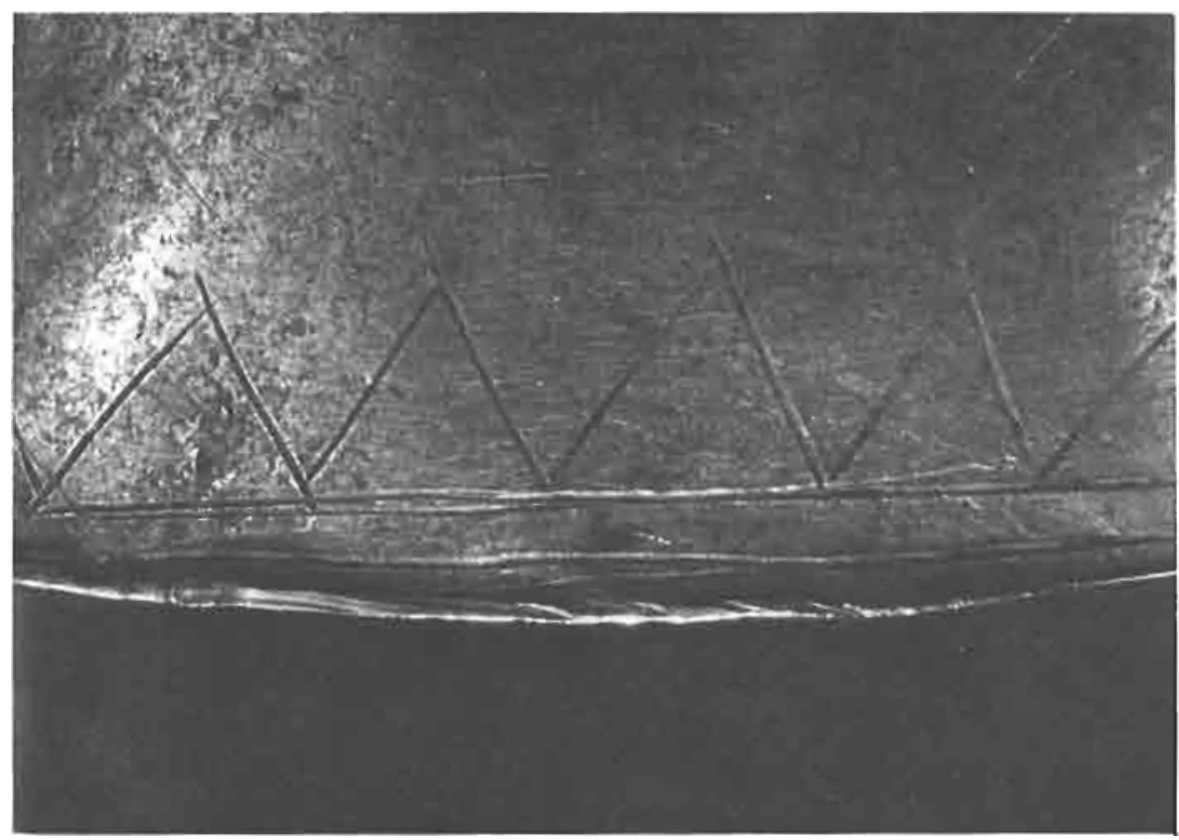

decorating gorgets, not only au repoussé and with a chisel, but also by the attaching to them of large discs using strands of gold thread. Larger accessories were also often decorated with delicate engravings executed with a compass (Figure 11). Lavish gold jewellery of these types was, for the greater part, restricted to Ireland and was not a feature of jewellery from other regions of Western Europe. On the contrary, most such regions - for example, Brittany, which in preceding times was relatively rich in gold - have yielded little from this period in the way of jewellery of note, other than a few collections of beaten bracelets and lesser ornaments (Figures 12 and 13). (10)

Some of the techniques of working in gold which characterized the Bronze Age survived that age in certain areas, though always for the production of jewellery which was
Fig. 14 This massive torc neckpiece from Evora, Portugal, weighs $2.130 \mathrm{~kg}$. It is covered with geometrically shaped incisions like many bronze ornaments of its period. In contrast, most gold rings and bracelets were made with smooth surfaces. Late Bronze Age

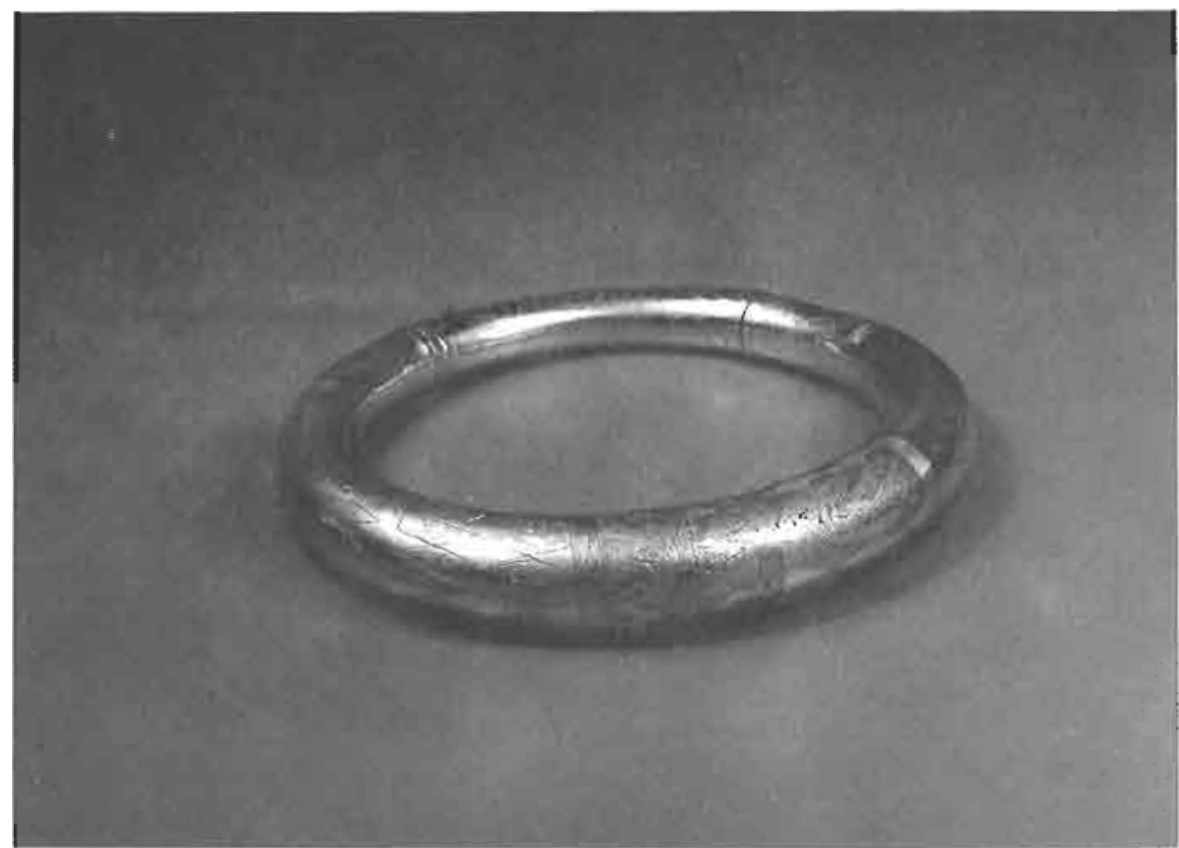



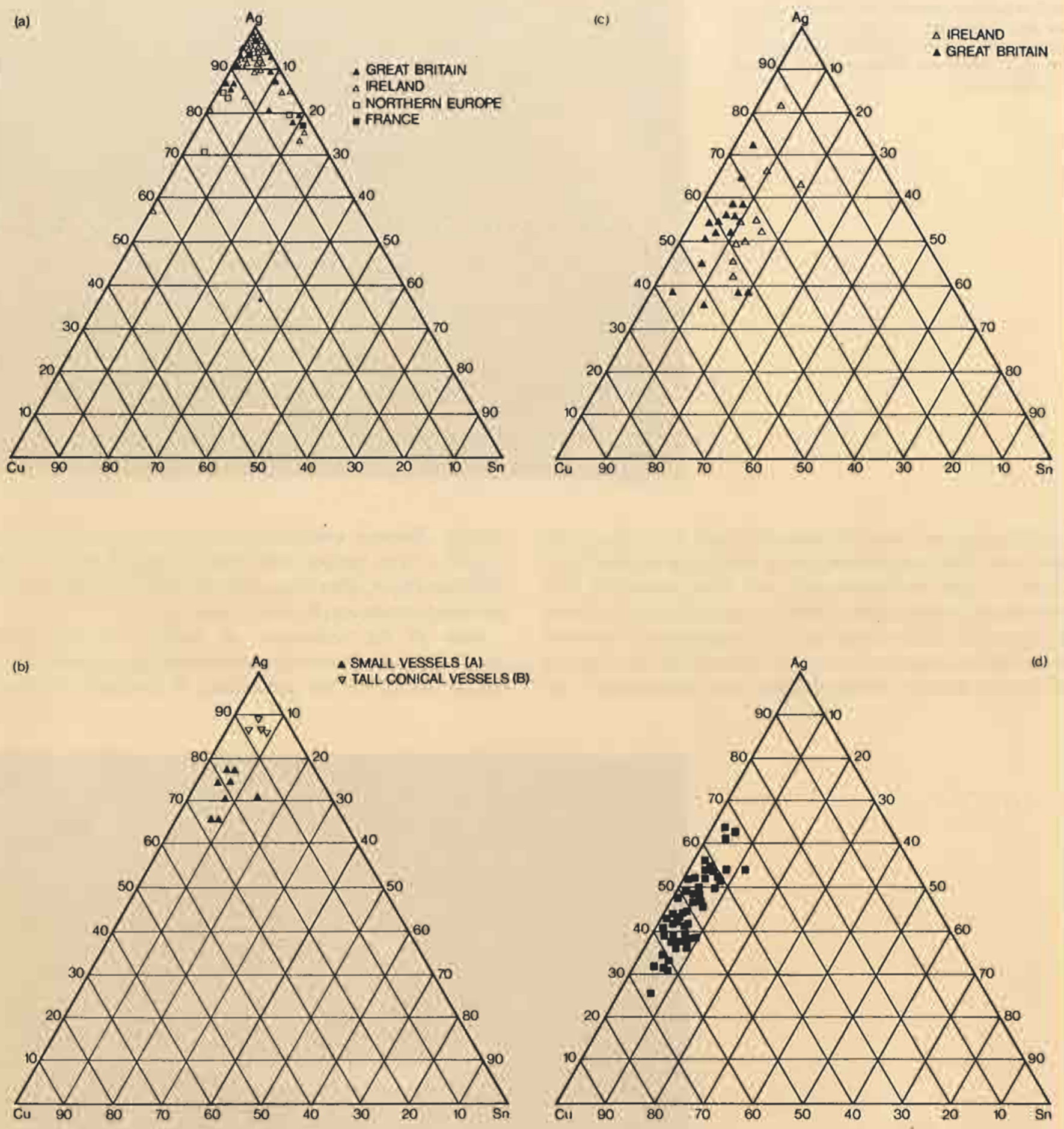

Fig. 15. Schematic representation of the silver, copper and tin contents of gold alloy artifacts found in different regions throughout Western Europe. In (a) the alloy compositions of 'lunules' do not appear to be characterized by the region in which they were found, The compositions of the small gold vessels, $A$, shown in (b) are fairly uniform and differ from those of the taller, conical vessels, B. The compositions of the long bar-torcs of Britain and Ireland shown in (c) show that the tin contents of the specimens are characterized by the region in which they were produced. Irish 'hair-ring' gold compositions (Late Bronze Age) shown in (d) all indicate the alloys to be high in copper 
traditional in type. In Southern Germany, for example, gold vessels were still being made not only at the end of the Bronze Age but also during the first Iron Age period (which followed); similar vessels produced after 1000 B.C. and decorated especially with simple bridle bits, have been recovered in other areas such as Spain.

In general, however, the great flourishing in the art and practice of making precious metal jewellery and ornaments, which spread throughout most of Europe in the Bronze Age, had died away by the end of the 8 th century. During the Iron Age which followed, gold apparently was much less available and it became more an exclusive attribute of 'princes' and their funerary wealth. It played a much smaller role in the lives of communities and ordinary people than appears to have been the case previously. In any event, the production of heavy and massive ornaments and jewellery (Figure 14) then came to an end and the emphasis thenceforth was to be on the techniques of using gold in the form of leaf and foil, and upon the artistic exploitation of these for decorative purposes.

\section{Gold Alloy Compositions}

The compositions of the golds used in ancient jewellery production can be determined spectrographically and the results provide a means of studying various aspects of ancient gold technology, including principally those related to the methods of acquisition of the primary metal. Some examples are given here which illustrate the types of conclusions that can be drawn from data on the proportions of silver, copper and tin determined in this way on gold samples from individual pieces.

Figure 15(a) shows a schematic representation of the silver, copper and tin contents of 'lunules'. Those from the different regions are not distinguished by characteristic compositions. In this respect it must be borne in mind, that the bulk of the gold used may have been derived from gold nuggets sufficiently large to be substantially free from a mixture with tin. Some gold used, however, and especially that with high tin content, may have been made from fine gold grains collected from rivers containing grains of the tin ore, cassiterite. Since the latter has a high specific gravity, grains of it would almost certainly have been collected together with the gold grains.

Figure 15(b) represents schematically the composition of gold vessels from Germany and northern Europe. The golds of the small vessels (A) appear fairly uniform in composition and differ from the golds of the tall conical vessels (B), such as that shown in Figure 8, of the Middle Bronze Age.

In Figure 15(c) are shown the compositions of the golds of the long bar-torcs of Britain and Ireland. Those of Irish specimens are distinguished from those of British specimens by their higher content of tin. These are from the Middle Bronze Age or the beginning of the Late Bronze Age $(1,2)$.

The compositions of the gold of 'hair-rings' the Late Bronze
Age from Ireland are shown schematically in Figure 15(d). They all show a high copper content. These copper-containing alloys which were in general use around 800 B.C. began to appear during the Middle Bronze Age $(1,2)$.

\section{References}

1 A. Hartmann, 'Prähistorische Goldfunde aus Europa' , Part 1, 1970 and Part 2, 1982, Studien für den Aufängen der Metallurgie, Berlin

2 J.J. Taylor, 'Bronze Age Goldwork of the British Isles', Cambridge University Press, 1980

3 C. Eluère, 'Les Ors Préhistoriques - l' Agc des Bronze en France 2', Picard, Paris, 1982

4 G. Eogan, 'Lock Rings of the Latc Bronze Age', Proc. Roy. Irish Acad., 1969, 67, 129-195

5 M. Almagro-Gorbea, 'Orfebreria del Bronze Final in la Peninsula Iberica...' 'Trabajos de Prehistorica', Chap. XXXI, pp. 39-90, 1974

6 C. Eluère, 'Les Premiers Ors de France', Bull. Soc. Préhist. Francaise, 1977, 74, 390-419

7 See (2), p. 27

8 See (2), p. 11

9 W. Menghin and P. Schaucr 'Magisches Gold', Germanisches Nationalmuseum, Nuremberg, 1977, pp. 45-50

10 C. Eluère, Archéologia, 1982, 173, Dec., 19-25

\section{French Goldwork in Antiquity}

Les Ors Préhistoriques by Christinane eluêre, Picard, Paris, 1982, 287 pages, FF250

The more than 400 gold artifacts found in France and which have been dated as belonging to the period extending from the end of the $3 \mathrm{rd}$ millenium to the 8 th century B.C. are listed and indexed in this recent book by the author of the preceding article.

Eluère's book is abundantly illustrated with phorographs, macrophotographs and drawings. It therefore constitutes an important and valuable reference work in which is embodied all the information currently available on each prehistoric gold artifact from France. However, this compilation is more a beginning than an end. The closing chapters of the book, in which the author discusses the possible role of gold and various types of goldwork among the peoples of the Bronze Age, are revealing of our lack of knowledge in this area. Eluère's detailed contribution provides those interested in studying the role of gold in prehistoric times more deeply with a comprehensive and well documented record of all the objects which have been recovered in France to date. 